\title{
Future changes in maximum temperature using the statistical downscaling model (SDSM) at selected stations of Iran
}

\author{
Mohsen Abbasnia ${ }^{1} \cdot$ Hüseyin Toros ${ }^{2}$
}

Received: 26 February 2016/ Accepted: 18 March 2016/Published online: 4 April 2016

(C) Springer International Publishing Switzerland 2016

\begin{abstract}
In the 21st century, climate change in the dry lands is considerate to be one of the greatest environmental threats to the world. This study presents the projection of future changes in maximum temperatures under A2, A1B and B1 SRES of the CGCM3 outputs using the statistical downscaling model (SDSM) in the 7 selected station over Iran during the two future periods (2041-70 and 2071-99). For this purpose, after examining the ability of SDSM in simulation of the basic period climate (1981-2010), the daily maximum temperature for future decades was downscaled by considering the uncertainty in 7 synoptic stations as climatic representatives of Iran. In uncertainties analysis related to model-scenarios, it was found that CGCM3 model under scenario B1 had the best performance in the simulation of future maximum temperatures among all of the scenarios. The findings showed that average maximum temperature at study stations over Iran will be increased between 0.3 and $3.5^{\circ} \mathrm{C}$. Also this maximum temperature changes will be more severe increased based on scenario A2 compared to other scenarios of the CGCM3 model.
\end{abstract}

Keywords Climate projection - Maximum temperature changes $\cdot$ Iran $\cdot$ Statistical downscaling model $\cdot$ SDSM

Mohsen Abbasnia

Am_abbasnia@pgs.usb.ac.ir; Abbasnai@itu.edu.tr

Hüseyin Toros

toros@itu.edu.tr

1 Department of Physical Geography and Climatology, University of Sistan and Baluchestan,

P. O. Box 987-98135, Zahedan, Iran

2 Department of Meteorology, Istanbul Technical University, Maslak, 34469 Istanbul, Turkey

\section{Introduction}

In arid and semi arid regions, the observed climatic instability is an unpredictable and complex phenomenon mainly attributed to human activity and in particular to gas emissions, which seem to influence the global warming of the planet. The temperature variations in arid and humid climates have been observed in most regions of the planet. So that, temperature changes in the dry lands will accelerate the process of desertification. According to the 5th Assessment Report (AR5) of the Intergovernmental Panel on Climate Change (IPCC), global average temperature has shown a $0.85{ }^{\circ} \mathrm{C}$ increase over the period of 1800-2012 (IPCC 2013), and a $0.18-0.74{ }^{\circ} \mathrm{C}$ increase during the last 100 years (1906-2005) (IPCC 2007). Also, this trend in global warming is predicted to likely increase during the 21 st century under all the representative concentration pathways (RCPs). This is probably due to the effects of industrialization that has increased greenhouse gas emissions. The intense interest in climate change has stimulated detailed studies of temperature records in many areas of the world. So far, extensive studies have been conducted in different countries with regarding to temperature trend during the current period. So that, these studies in the perspective of spatial scale, it can be grouped into three studies: regional (Kadioğlu et al. 2001; Toros 2012; Whan et al. 2014; Toros et al. 2015), hemispherical (Jones 1994; Stern and Kaufmann 2000; Jones and Moberg 2003) and planetary (Horton 1995; Rahmstorf and Ganopolski 1999). In all these studies have investigated the status quo of temperature parameters, while a few researches has been done regarding the impacts of climate change on the temperatures trend in the coming decades.

In order understanding of the global warming effects and climate change during the future periods, can be used the output of general circulation models (GCM). So that, 
average global temperature will be increased in terms of various models-scenarios outputs during the future periods due to emission of greenhouse gases. All of these models depend on the time and has a three-dimensional numerical simulation from atmospheric motions, heat exchanges and interactions among ice, ocean and land (Dracup and Vicuna 2005). Therefore, increasing global temperature in the most parts of the world due to climate change effects has provided various results and predictions of GCM outputs. In other words, according to GCM models, global temperatures till 2100 will be increased in a range from 2 to $4.5^{\circ} \mathrm{C}$ (IPCC 2007). Since, temporal and spatial resolution of GCM models is coarse so that downscaling methods is necessary to convert the GCM outputs to local variables in scale of observation stations (Salon et al. 2008). For this purpose, dynamical and statistical methods can be used. Furthermore, dynamic models require to ultra-fast laboratory facilities that most countries are lacking, therefore researcher's attention are directed to statistical models. In this regard, the statistical downscaling model (SDSM) by Wilby et al. (2002) as its builders has been considered as a perfect tool for statistical downscaling as well as described the functionality of the SDSM model in predicting and producing the present and future climatic data. So far, extensive researches in the field of climate change and global warming have been used the SDSM model for downscaling process (Chu et al. 2010; Huang et al. 2011; Mahmood and Babel 2013). At a regional scale most studies seeking to detect the effects of climate change on climatic variables and temperature extreme are conducted in East and South-East Asia, China, India and Pakistan (Islam et al. 2009; Gu et al. 2012; Mahmood and Babel 2014). While, future changes in temperature extreme and extreme climatic phenomena is necessary in any regions due to have information about negative impacts on human society and the natural environment than the changes in mean climate. The report of Iran Meteorological Organization (IRIMO 2012) showing effects on mitigation and adaptation to climatic extremes indicated that there is an increase in extreme climate events in Iran, particularly temperature extremes. Therefore, in this study it has been tried to evaluate the maximum temperature changes under global warming in Iran during the near future (2041-70) and the far future (2071-99), by using of the statistical downscaling method (SDSM) on the output of CGCM3T63 Model under existing scenarios (A2, A1B and B1).

\section{Study area}

Iran is geographically uneven located in the arid and semiarid area in the Middle East and the average height of sea level is around 1250 meters. There are high mountains and diverse topography that has caused the temperature distribution in Iran has not followed the regular pattern. However, Iran temperature from North to South and from West to East is generally increasing due to the characteristics of mountains that there are in the North and West of the country. In this study, in order to gain a perspective of temperature changes has been studied 7 synoptic stations as representative of $b$ climate zones over Iran (Fig. 1).

\section{Materials and methods}

\section{Data analysis}

To assess maximum temperature changes in the coming decades, the SDSM model has been used as a tool for handling statistical downscaling data on GCM outputs. Downscaling process is an agent that establishes relationship between climate variables on a local scale (predicted) and large-scale atmospheric variables (predictors) (Wilby and Dawson 2013). Therefore, to do this study and achieve a prospect of daily maximum temperature variations in station scales, two sets of data are needed: (1) daily maximum temperatures that prepared by Iran Meteorological Organization (via http://www.irimo.ir) at 7 synoptic stations in the range of Iran's climatic regions during the observational period 1981-2010. The accuracy of this data at the significance level of $95 \%$ was approved based on data adequacy test, homogeneity of Run test and normality of Kolmogorov-Smirnov test. (2) Daily large-scale atmospheric variables as predictors that prepared from the National Center for Environmental Prediction (NCEP) during the observation periods and also outputs of CGCM3 model under existing scenarios in similar observation periods and in future periods (2041-70 and 2071-99) that extracted from the Canadian Climate Change Scenarios Network (CCCSN). Table 1 indicates that the nearest grid box numbers to the study stations for extracting the CGCM3 data regarding to the longitude and latitude of study area.

Then the large-scale predictors were normalized rather than average and standard deviations of the observation period (1981-2010). Table 2 summarizes the most important features of CGCM3 model as input of the SDSM software (IPCC 2007).

\section{Statistical downscaling model (SDSM)}

Statistical downscaling model has been developed by Wilby et al. (2002) as an appropriate tool for statistical downscaling and even producing meteorological data using a combination of stochastic weather generator (SWG) and multiple linear regression (MLR). It is the one of the best 
Fig. 1 Topography map and distribution of the selected stations in Iran

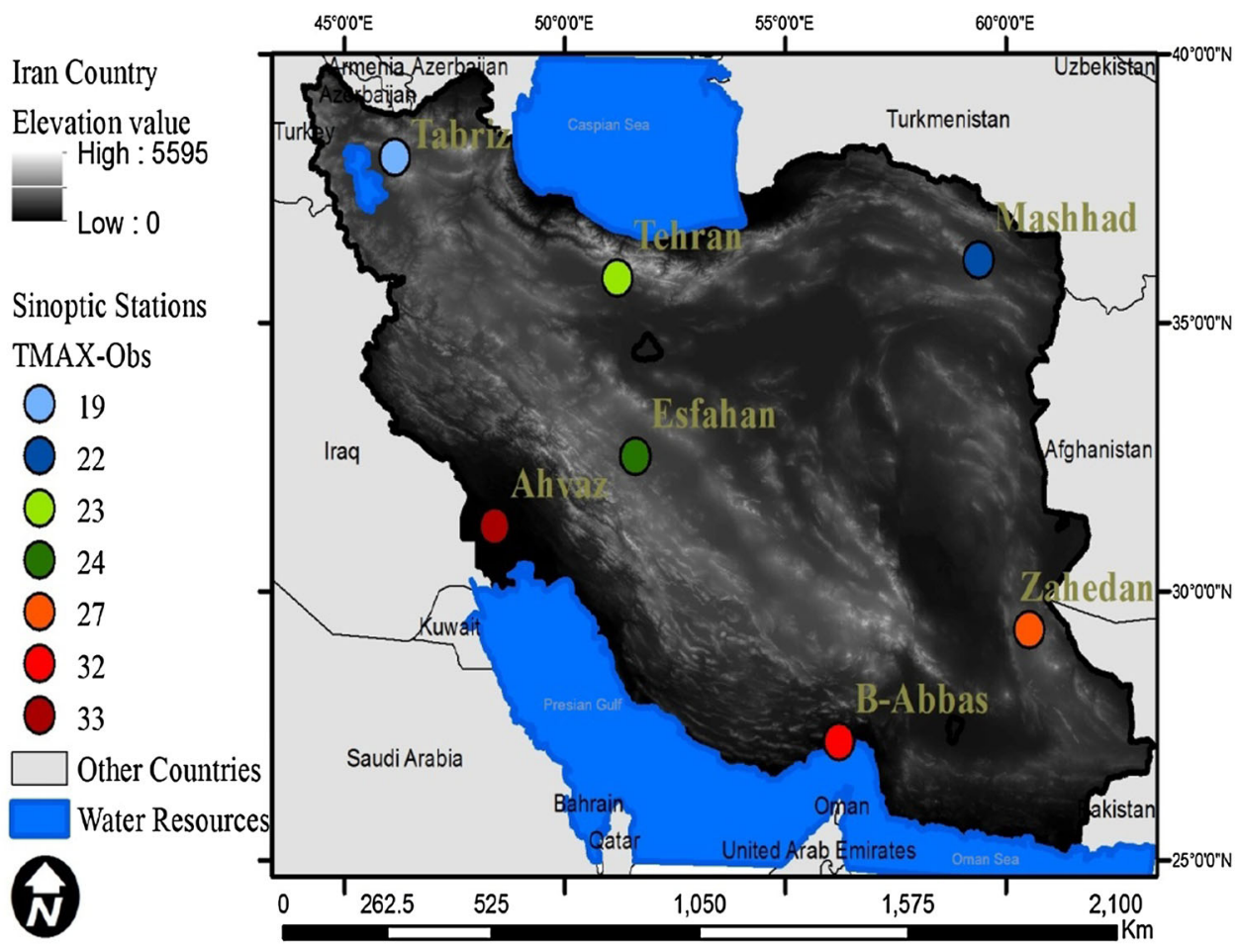

\begin{tabular}{llllllll}
\hline GCM & Mashhad & Zahedan & Tehran & Esfahan & B-Abbas & Ahvaz & Tabriz \\
\hline CGCM3 (T63) & & & & & & & \\
X number & 21 & 22 & 18 & 18 & 20 & 17 & 16 \\
Y number & 45 & 43 & 45 & 44 & 42 & 44 & 44 \\
\hline
\end{tabular}

Table 1 The latitude and longitude box numbering of CGCM3 model in study stations

Table 2 The characteristic of study GCM model as SDSM software input

\begin{tabular}{lllll}
\hline GCM & IPCC & SRES & Resolution & Reference \\
\hline CGCM3-T63 & IPCC4 & A2, B1, A1B & $2.81^{\circ} \times 2.81^{\circ}$ & AR4, Canadian Centre for Climate Modeling and Analysis (CCCma), Canada
\end{tabular}

models in the classification of various downscaling methods. The basis of this method is designing multiple regression models. So that in this method, in order to simulate climatic parameters for any time scale period (monthly, seasonally or annually), a multivariate linear regression model is developed between large-scale predictors (as independent variables) and predicted climatic variables at station scale (as dependent variable) and through following steps:

\section{Monitoring and screen variables}

In this step, since maximum temperature time series is normally distributed so it is considered an unconditional variable. Therefore, to select multivariate regression model in SDSM software, the directly relationship is considered between observational maximum temperature as predicted variable and large scale predictors as independent variables. So, to identify and select suitable predictors with strongest significant correlation with observational temperature at each study station, correlation analysis are used between predictors and predicted that is including correlation matrix analysis, partial correlation, scatter plot as well as the percentage of variance explained among variables. Thus, in this study, the best predictors were selected based on the results of correlation analysis for selecting the best multiple regression models at each local stations.

Table 3 summarizes the results of partial correlation between selected predictor variables from CGCM3 model and maximum temperature variable at each station. Therefore, the predictors in following Table represent a compromise maximum overlap between NCEP and 
Table 3 The partial correlations between the selected predictors of CGCM3 model and the maximum temperature at each station over the observation period

\begin{tabular}{|c|c|c|c|c|c|c|c|c|}
\hline \multirow[t]{2}{*}{ Predictor } & \multirow[t]{2}{*}{ Description } & \multicolumn{7}{|l|}{ Station } \\
\hline & & Tehran & Tabriz & Esfahan & Ahvaz & Zahedan & Mashhad & B-Abbas \\
\hline Mslp & Mean sea level pressure & -0.28 & -0.28 & -0.03 & -0.05 & -0.11 & -0.23 & - \\
\hline P500 & Geopotential height $(500 \mathrm{hPa})$ & 0.43 & 0.48 & 0.44 & 0.14 & 0.55 & 0.41 & 0.28 \\
\hline P850 & Geopotential height $(850 \mathrm{hPa})$ & - & - & -0.10 & - & -0.03 & - & - \\
\hline P8_u & U Wind $(850 \mathrm{hPa})$ & -0.28 & 0.13 & - & - & - & -0.07 & - \\
\hline R850 & Relative humidity $(850 \mathrm{hPa})$ & -0.07 & -0.06 & -0.26 & -0.36 & -0.29 & -0.28 & -0.14 \\
\hline Shum & Near surface specific humidity & - & 0.09 & - & - & - & - & - \\
\hline Temp & Mean temperature at $2 \mathrm{~m}$ & 0.29 & 0.18 & 0.26 & 0.51 & 0.17 & 0.12 & 0.62 \\
\hline
\end{tabular}

CGCM3 achieves, as well as a range of choice for downscaling.

\section{Calibration and validation}

To evaluate performance of multivariate regression models that is resulted from validation step of SDSM model, there are some measurement errors for calibration of predictions outputs. In this study, to evaluate accuracy and relative comparison have been done on the results of multivariate regression model of prediction at each station during the base period (1981-2010). So, in order to assess relative comparison in results of multivariate regression models with observation maximum temperature values at each station during the base period (1981-2010) have been used the spatial and temporal standard error (SE) of predictions, $\mathrm{R}$ square $\left(\mathrm{R}^{2}\right)$, mean absolute error (MAE) and mean bias error (MBE). Overall, results of different statistical measurement error showed that the final regression equations has acceptable accuracy to predict daily maximum temperature during future decades based on large-scale atmospheric variables as independent variables from each GCM models (Table 4). Also, statistical analysis of the t test in any time scale (monthly, seasonally and annually) showed that there is no significant difference in critical level of 0.05 between final prediction variables and observational values of maximum temperature at each study station during the observation period (1981-2010).

\section{Climatic scenarios generation}

Since climate change will be highly dependent on human activities in the future, IPCC considers about 40 emission scenarios issued from special report on emission scenarios (SRES) that is related to amount of greenhouse gases emissions, land use, technology development and other human activities. The number of emission scenarios is increasing with regard to the various consideration in future but the most important family in the emission
Table 4 Results of calibration and validation phase of SDSM model in observation period (1981-2010)

\begin{tabular}{lllll}
\hline Station & $\mathrm{SE}$ & $\mathrm{R}^{2}$ & $\mathrm{MAE}$ & $\mathrm{MBE}$ \\
\hline Tehran & 2.25 & 0.62 & 1.84 & 0.04 \\
Tabriz & 2.53 & 0.61 & 2 & 0 \\
Esfahan & 2.20 & 0.55 & 2.45 & 0 \\
Ahvaz & 2.01 & 0.59 & 2.2 & -0.002 \\
Zahedan & 2.20 & 0.61 & 1.7 & -0.23 \\
Mashhad & 3.42 & 0.48 & 2.8 & -0.004 \\
B-Abbas & 1.80 & 0.45 & 2 & 0.01 \\
\hline
\end{tabular}

scenarios and their characteristics defined by IPCC are A1, A1F1, A1B, A1T, A2, B1, and B2 (IPCC 2007). Accordingly, also in SDSM software producing future climate scenarios about changes in local parameters will be based on various emission scenarios in the future decades. In this stage of the study, according to final regression equations and calibrated multivariate regression models between various predictors of large-scale variables with maximum temperature variable at study station scales in the observation period, the process of downscaling will be done on outputs of CGCM3 Model under various emissions scenarios during future periods. Thus, daily maximum temperature time series at station scale is simulated and produced for future period.

\section{Uncertainty analysis}

In climate change studies should be considered various uncertainties of modeling to achieve more reliable results (Semenov and Stratonovitch 2010). In assessing climate change, there are also many sources of uncertainty that is categorized into two main groups. The first case is related to dynamic structure of GCMs and their computational process that the contribution of this type of uncertainty gradually decreases with the passage of time due to increasing quality and accuracy of GCM models. The 
second case is related to amount of greenhouse gas emissions (Covey et al. 2003). Generally in this study, to evaluate the uncertainty arising from using of various model-scenarios is used mean observed temperature method (Eq. 1) (for the more details refer to Hashemi-Ana et al. 2015).

$W_{i, j}=\frac{\frac{1}{\Delta T_{i, j}}}{\sum_{j=1}^{n}\left(1 / \Delta T_{i, j}\right)}$

In this equation, $W_{i, j}$ is the weight given to each modelscenarios (j), $\Delta T_{i, j}$ is difference between average of simulated maximum temperature in the feature periods from average of observational maximum temperature for each day (i) and n, is total number of model-scenarios.

Thus in this study, the probability weights that is related to ability of any used models-scenarios about simulation of maximum temperature was calculated. According to Table 5, it is clear that simulation of maximum temperature based on CGCM3 and under the emission scenarios B1 has better performance in all stations. In other words, the results of B1 scenario allocates the highest probability of occurrences than other model-scenarios.

Then, according to the range of uncertainty that is associated with output of all various model-scenarios, the Assemble Scenario with regard to the weight of each models-scenarios were produced to get a similar and comprehensive scenario of maximum temperature changes at local scale in Iran during future decades (Eq. 2).

$S R E_{\text {Assemble }}=\sum_{j=1}^{n}\left(\Delta T_{i, j} \times W_{i, j}\right)$

In this regard, the components of above equation are the same with Eq. 4.

Table 5 Probability occurrence of each scenario in the simulation of maximum temperature during the future periods

\begin{tabular}{|c|c|c|c|c|c|c|}
\hline CGCM3 model & SRES & & & & & \\
\hline Future period & $2041-$ & & & 2071 & & \\
\hline Station & $\mathrm{A} 2$ & B1 & A1B & $\mathrm{A} 2$ & B1 & A1B \\
\hline Tehran & 0.29 & 0.42 & 0.30 & 0.23 & 0.45 & 0.32 \\
\hline Tabriz & 0.27 & 0.42 & 0.31 & 0.22 & 0.46 & 0.32 \\
\hline Esfahan & 0.26 & 0.48 & 0.26 & 0.19 & 0.48 & 0.33 \\
\hline Ahvaz & 0.24 & 0.51 & 0.25 & 0.19 & 0.51 & 0.30 \\
\hline Zahedan & 0.26 & 0.51 & 0.24 & 0.21 & 0.50 & 0.30 \\
\hline Mashhad & 0.08 & 0.84 & 0.08 & 0.17 & 0.54 & 0.29 \\
\hline B-Abbas & 0.28 & 0.47 & 0.25 & 0.22 & 0.44 & 0.34 \\
\hline
\end{tabular}

\section{Results and discussion}

In this study after assessing ability of the SDSM, daily maximum temperature of future decades were downscaled based outputs of CGCM3 model at a station scale in Iran. Then, simulation results of daily maximum temperature were extracted based on each model-scenarios with regarding to uncertainty analysis in two future periods (2041-70 and 2071-99). Finally, maximum temperature changes based on each model-scenarios in future periods were compared than the observation period (1981-2010). It is worth noting that the obtained results based on each model-scenarios represent an increase in maximum temperature at all study stations during the future decades. However, this increasing in maximum temperature is different at each station and for each future period (Figs. 2 and 3).

After uncertainty analysis onto the outputs of all modelscenarios during the coming periods at station scale, it was found that the lowest increase in maximum temperature with the minimum range of uncertainty is observed at B-Abbas and Ahvaz stations which are located in the southern regions of Iran and vice versa, the greatest increase in maximum temperature with the maximum uncertainty range at Tabriz and Tehran stations which are located in the northern regions of Iran. In other words, by analyzing of the maximum temperature changes in the middle of current century (2041-70), it was found that the average maximum temperatures will be increased around 0.06 to $2.47{ }^{\circ} \mathrm{C}$ based on the all of scenarios in Iran. Also, the greatest increase in maximum temperature is observed based on scenario A2 and vice versa, the lowest increase in maximum temperature is observed based on scenario B1 as well as simulation results shown that the rising in

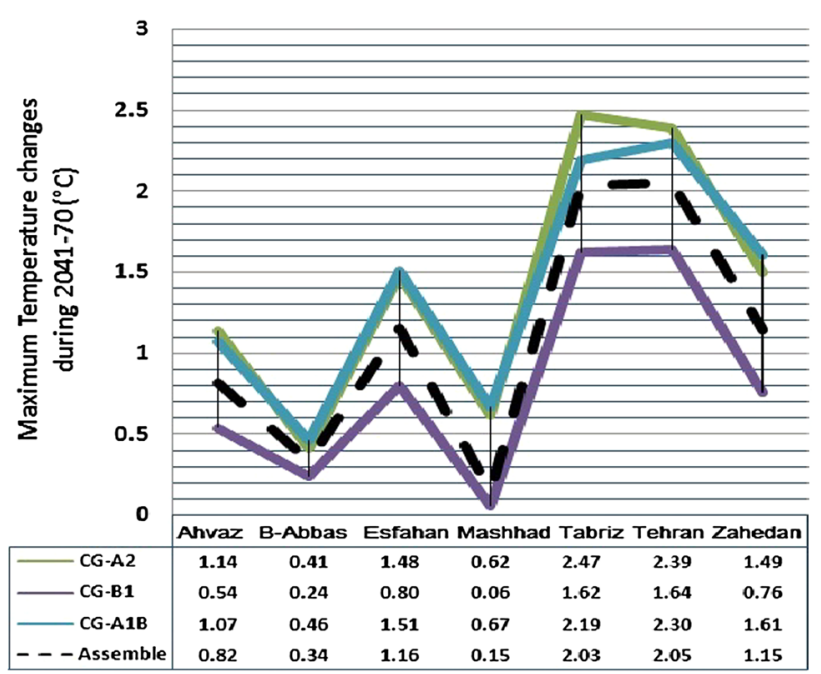

Fig. 2 The uncertainty of model- scenarios resulted from changes simulation of maximum temperature in the near future 


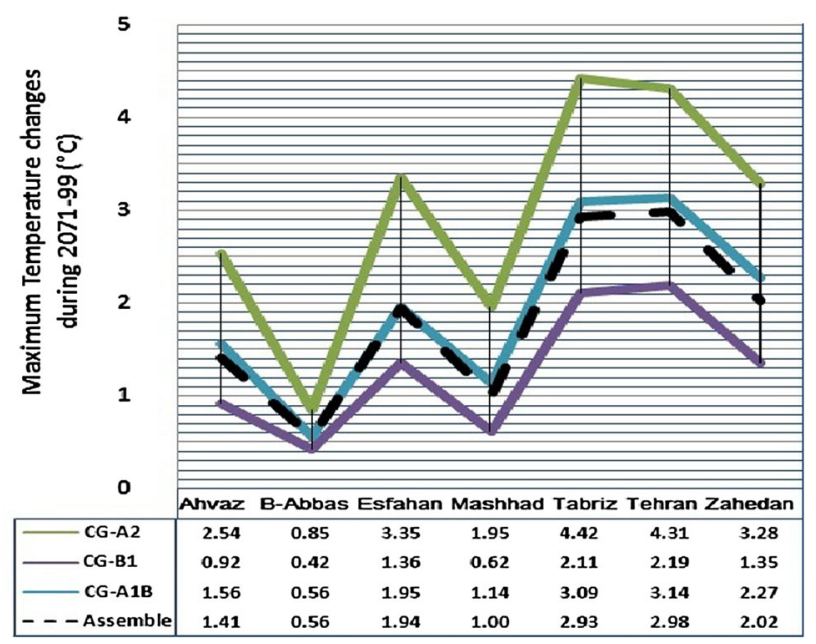

Fig. 3 The uncertainty of model- scenarios resulted from changes simulation of maximum temperature in the Far future

maximum temperature based on scenario $\mathrm{B} 1$ is lower than scenario A2. In this respect, based on various scenarios of CGCM3 model, the greatest increase in maximum temperature is observed at Tabriz station which is located in the northwestern regions of Iran and vice versa, the lowest increase in maximum temperatures is observed in Mashhad and B-Abbas stations which are located in the central and southern regions of Iran.

In other hand, increasing the maximum temperature during the period of end-century (2071-99) has similar spatial distribution in relation to the period of mid-century (2041-70). So what are important in comparative evaluation of maximum temperature changes between the two future periods will be changes in the intensity values of maximum temperature. In other words, at the end of 21 st century will be added intensity values of rising maximum temperature in compared to its middle period, so that this increase in maximum temperature will be between 0.42 and $4.42{ }^{\circ} \mathrm{C}$. Also at the end of 21st century (2071-99), the greatest increase in maximum temperature based on scenario A2 is observed at Tabriz station which in the north-west of Iran and vice versa, the lowest increase in maximum temperature based on scenario B1 is observed at B-Abbas station in the southern regions of Iran. Therefore, based on simulation results of scenario A2 in compared to scenario B1, future trend of maximum temperature has been increased and under various study scenarios at study stations in Iran.

\section{Conclusion}

Climate change especially rising temperatures in arid and semi arid regions are one of the important environmental issues in human society that has allocated many studies in recent years. Thus, in this study for necessity recognition and comparative evaluation about climate change effects on the occurrence of daily maximum temperatures during the two future periods (2041-70 and 2071-99), it has been tried that the data of CGCM3-T63 model under existing scenarios (A2, A1B, B1) are downscaled by using of the SDSM model. As simulation results about increasing of maximum temperatures in future decades showed that the future changes of maximum temperature will be more intensified based on scenario A2 rather than the all scenarios of CGCM3 model. So, after taking into uncertainty range that is related to outputs of all model-scenarios, the results of Assemble scenario showed that the average of rising maximum temperature variation will be increased between 0.15 and $2{ }^{\circ} \mathrm{C}$ for near future period (2041-70) and between 0.5 and $3{ }^{\circ} \mathrm{C}$ for far future period (2071-99) in Iran. In other words, based on simulation results of all model-scenarios in study stations, maximum temperature of Iran during the middle and the end of twenty-first century will be increased an average of between 0.3 and $3.5^{\circ} \mathrm{C}$ compared to the base period (1981-2010). Also in terms of geographic distribution, the greatest increase in maximum temperature is observed at Tabriz station which is located in the northwestern mountainous of Iran and vice versa, the lowest increase is observed at B-Abbas station which is located in the southern coasts of Iran. In general, what can be obtained from the survey results of this study for all output of various scenarios is that the mountainous stations which is located in the more northern latitudes with drier climate will be more faced to risk of the rising maximum temperatures during the coming decades.

Acknowledgments The authors would like to acknowledge from the Iran Meteorological Organization for providing for providing the daily climatic data and technical supports. Thanks also to Prof. Robert Wilby, in related to preparing and sending the daily large-scale atmospheric variables in the extent of Iran.

\section{References}

Chu JT, Xia J, Xu CY, Singh VP (2010) Statistical downscaling of daily mean temperature, pan evaporation and precipitation for climate change scenarios in Haihe River, China. Theor Appl Climatol 99(1-2):149-161. doi:10.1007/s00704-009-0129-6

Covey C, Achuta-Rao KM, Cubasch U, Jones P, Lambert SJ, Mann ME, Phillips TJ, Taylor KE (2003) An overview of results from the coupled model inter comparison project. Global Planet Change 37(1):103-133. doi:10.1016/S0921-8181(02)00193-5

Dracup JA, Vicuna S (2005) An overview of hydrology and water resources studies on climate change: the California experience. In: World Water Congress (May: 15-19), Anchorage, Alaska, pp 1-12. doi:10.1061/40792(173)483

Gu H, Wang G, Yu Z, Mei R (2012) Assessing future climate changes and extreme indicators in east and south Asia using the RegCM4 regional climate model. Clim Change 114(2):301-317. doi:10. 1007/s10584-012-0411-y 
Hashemi-Ana SK, Khosravi M, Tavousi T (2015) Validation of AOGCMs capabilities for simulation length of dry spells under the climate change in Southwestern area of Iran. Open J Air Pollut 4(02):76-85. doi:10.4236/ojap.2015.42008

Horton B (1995) Geographical distribution of changes in maximum and minimum temperatures. Atmos Res 37(1):101-117. doi:10. 1016/0169-8095(94)00083-P

Huang J, Zhang J, Zhang Z, Xu C, Wang B, Yao J (2011) Estimation of future precipitation change in the Yangtze River basin by using statistical downscaling method. Stoch Environ Res Risk Assess 25(6):781-792. doi:10.1007/s00477-010-0441-9

IPCC (2007) Climate change: the physical science basis. Contribution of working group I to the fourth assessment, report of the intergovernmental panel on Climate change. Cambridge University Press, Cambridge, p 996

IPCC (2013) Climate change 2013: the physical science basis. Contribution of working group I to the fifth assessment, report of the intergovernmental panel on Climate change. Cambridge University Press, Cambridge, p 1550

Islam S, Rehman N, Sheikh MM (2009) Future change in the frequency of warm and cold spells over Pakistan simulated by the PRECIS regional climate model. J Clim Change 94(1-2):35-45. doi:10.1007/s10584-009-9557-7

Jones PD (1994) Hemispheric surface air temperature variations: a reanalysis and an update to 1993. J Clim 7(11):1794-1802. doi:10.1175/1520-0442(1994)007<1794:HSATVA > 2.0.CO;2

Jones PD, Moberg A (2003) Hemispheric and large-scale surface air temperature variations: an extensive revision and an update to 2001. J Clim 16(2):206-223. doi:10.1175/1520-0442(2003) $016<0206:$ HALSSA $>2.0 . \mathrm{CO} ; 2$

Kadioğlu M, Şen Z, Gültekin L (2001) Variations and trends in Turkish seasonal heating and cooling degree-days. J Clim Change 49(1-2):209-223. doi:10.1023/A:1010637209766

Mahmood R, Babel MS (2013) Evaluation of SDSM developed by annual and monthly sub-models for downscaling temperature and precipitation in the Jhelum basin, Pakistan and India. Theor Appl Climatol 113(1-2):27-44. doi:10.1007/s00704-012-0765-0
Mahmood R, Babel MS (2014) Future changes in extreme temperature events using the statistical downscaling model (SDSM) in the trans-boundary region of the Jhelum river basin. Weather Clim Extremes 5:56-66. doi:10.1016/j.wace.2014.09.001

Rahmstorf S, Ganopolski A (1999) Long-term global warming scenarios computed with an efficient coupled climate model. J Clim Change 43(2):353-367. doi:10.1023/A:1005474526406

Salon S, Cossarini G, Libralato S, Gao Solidoro XC, Giorgi F (2008) Downscaling experiment for the Venice lagoon. I. Validation of the present-day precipitation climatology. J Clim Res 38(1): 31-41. doi:10.3354/cr00757

Semenov MA, Stratonovitch P (2010) Use of multi-model ensembles from global climate models for assessment of climate change impacts. J Clim Res 41(1):1-14. doi:10.3354/cr00836

Stern DI, Kaufmann RK (2000) Detecting a global warming signal in hemispheric temperature series: a structural time series analysis. J Clim Change 47(4):411-438. doi:10.1023/A:1005672231474

Toros H (2012) Spatial-temporal variation of daily extreme temperatures over Turkey. Int J Climatol 32(7):1047-1055. doi:10. $1002 /$ joc. 2325

Toros H, Tek A, Solum Ş, Yeniçeri DN, Söğüt AS, Oğuzhan B, Çağlar ZN, Okçu D, Kalafat AG, Giden F, Koyuncu H (2015) Climate trends and variations between 1912-2014 in Kandilli, Istanbul, VII. Atmospheric Science Symposium, 28-30 April 2015, Istanbul, pp 978-987

Whan K, Alexander LV, Imielska A et al (2014) Trends and variability of temperature extremes in the tropical Western Pacific. Int J Climatol 34(8):2585-2603. doi:10.1002/joc.3861

Wilby RL, Dawson CW (2013) The statistical downscaling model: insights from one decade of application. Int $\mathrm{J}$ Climatol 33(7):1707-1719. doi:10.1002/joc.3544

Wilby RL, Dawson CW, Barrow EM (2002) SDSM-A decision support tool for the assessment of regional climate change impacts. J Environ Model Softw 17(2):145-157. doi:10.1016/ S1364-8152(01)00060-3 